\title{
Peripheral retinal haemorrhages in long-duration insulin-dependent diabetes with minimal background retinopathy
}

\author{
M. S. ROY AND J. C. McCULLOCH \\ From the Department of Ophthalmology, University of Toronto, 1 Spadina Crescent, Toronto, \\ Ontario, Canada M5S 2J5
}

SUMmaRY Eight long-standing, well controlled insulin-dependent diabetics with little or no retinopathy at the posterior pole and no abnormality other than the diabetes had numerous peripheral retinal haemorrhages. Such changes were not observed in a nondiabetic control group matched for sex and age.

The early and main pathological changes in diabetic retinopathy are usually described in the posterior central portions of the eye, particularly temporal to the macula. ${ }^{2}$ Light microscopic examinations of trypsin digest preparations of specimens showing advanced retinopathy confirm this. But little information has been published on changes in the far periphery of the diabetic fundus.

Norton and Gutmann ${ }^{3}$ and Davis ${ }^{1}$ have drawn attention to the unique value of biomicroscopic examination of the retina in association with the study of fluorescein pictures for assessing early diabetic retinal lesions. We noted small haemorrhages in the periphery of the retina next to the ora serrata in cases of juvenile-onset insulin-dependent diabetes mellitus of long duration with minimal or no signs of diabetic retinopathy at the posterior pole. To assess if this was more than a chance observation these patients were compared with a matched control group of nondiabetic patients.

\section{Subjects and methods}

The experimental group of diabetic patients consisted of 4 men and 4 women. Their ages and the duration of diabetes are shown in Table 1 . All had juvenile-onset insulin-dependent diabetes and were well controlled with diet and insulin (Table 1 ). They received no medication other than insulin.

All 8 diabetic patients were part of a separate research project whose inclusion criteria required an Correspondence to Dr M. S. Roy. insulin-dependent diabetes mellitus of more than 25 years' duration. All patients had undergone an extensive medical assessment as part of that project. This included a detailed medical history, physical examination, and numerous investigations. Carbohydrate metabolism was assessed with repeated standard blood glucose with a Beckman analyser, continuous glucose monitoring measurements by means of a continuous-flow analyser as described by Albisser et al., ${ }^{4}$ urine glucose levels, and haemoglobin $A_{1} C$ assay. Fasting plasma cholesterol, triglycerides, and lipoprotein electrophoresis, and the levels of alanine and 12 different amino acids were studied. Hormonal blood level measurements included catecholamines, free insulin, $C$ peptide, glucagon, human growth hormone, somatostatin, pancreatic polypeptide, gastric inhibitory polypeptide, and cortisol. In the fasting patient human growth hormone, glucagon, and $C$ peptide levels were also measured after arginine infusion. Urinary $\mathrm{C}$ peptide excretion was measured. The presence and severity of diabetic complications were assessed quantitatively by measurement of nerve conduction velocities and kidney function. Platelet function, status of coagulation, and the fibrinolytic system were studied extensively in all patients.

The ophthalmological assessment included corrected visual acuity, measurement of intraocular pressure and central retinal artery diastolic pressures, and examination of the ocular media. Particular attention was given to the biomicroscopic examination of the fundus with the Goldmann 
Table 1 Age, duration of diabetes (years), and insulin requirements (number of units morning/evening)

\begin{tabular}{|c|c|c|c|c|c|c|c|c|}
\hline \multicolumn{8}{|c|}{ Diabetics } & \multirow{3}{*}{$\begin{array}{l}\text { Controls } \\
\text { Age }\end{array}$} \\
\hline \multirow[b]{2}{*}{ Sex } & \multirow[b]{2}{*}{ No. } & \multirow[b]{2}{*}{ Age } & \multirow[b]{2}{*}{ Duration } & \multicolumn{4}{|l|}{ Insulin } & \\
\hline & & & & Regular & $N P H$ & Lente & $P Z I$ & \\
\hline \multirow[t]{4}{*}{$\mathbf{M}$} & 1 & 49 & 47 & $11 / 0$ & & $12 / 10$ & & 44 \\
\hline & 2 & 39 & 26 & $10 / 0$ & & & $40 / 0$ & 36 \\
\hline & 3 & 49 & 33 & $15 / 10 / 10$ & & $0 / 15$ & & 54 \\
\hline & 4 & 66 & 53 & $12 / 5$ & & $12 / 0$ & & 63 \\
\hline \multirow[t]{4}{*}{$\mathbf{F}$} & 5 & 44 & 36 & $8 / 0$ & & $10 / 4$ & & 43 \\
\hline & 6 & 48 & 39 & $6 / 0$ & & $22 / 0$ & & 47 \\
\hline & 7 & $371 / 2$ & 30 & $6 / 0$ & & $22 / 0$ & & 32 \\
\hline & 8 & 40 & 32 & $14 / 0$ & $18 / 0$ & & & 42 \\
\hline
\end{tabular}

3-mirror contact lens. The retinal lesions were drawn on a fundus chart and correlated with the findings of fundus photographs and of fluorescein angiography performed on all patients. Visual fields were assessed with the Amsler grid and the Goldmann perimeter. Colour vision was tested with the Farnsworth 100-hue test.

The diabetic patients were matched for sex and age (within 5 years) with a nondiabetic control group of patients attending the regular refraction clinics. None of these control patients had a systemic or ocular disorder or received any medication. They had a complete ophthalmic examination, including biomicroscopy of the retina with the Goldmann 3-mirror contact lens, with a search for small peripheral lesions.

\section{Results}

General medical studies showed that all the diabetic patients had well controlled diabetes with only occasional hypoglycaemic episodes. The patients had no clinical signs of peripheral vascular disease. There were no bruits over the carotid arteries. The systemic and diastolic blood pressures were normal in all patients. Patients 3, 4, and 5 had evidence of a mild peripheral neuropathy on clinical and nerve conduction tests. There were no abnormalities of coagulation or in lipid or hormonal assays. Patients 1 , $2,3,4$, and 5 had undetectable urinary levels of $C$ peptide (normal value $36 \mu \mathrm{g} /$ day). Patients 6,7 , and 8 had urinary $C$ peptide levels ranging from 1.96 to 6.61 $\mu \mathrm{g} /$ day - still well below normal levels.

The general ophthalmic examination was noncontributory (Table 2). In patient 4 visual acuity was decreased to $20 / 40$ and $20 / 50$; this was related to nuclear opacities of the crystalline lenses. Patient 6 had some bilateral cortical lens opacities. However, in both patients the fundi were well seen. Patient 3

Table 2 Ophthalmic examination

\begin{tabular}{|c|c|c|c|c|c|c|c|c|}
\hline \multirow[b]{2}{*}{ No. } & \multicolumn{4}{|l|}{ Male } & \multicolumn{4}{|l|}{ Female } \\
\hline & 1 & 2 & 3 & 4 & 5 & 6 & 7 & 8 \\
\hline $\begin{array}{l}\text { Visual acuity OU } \\
\text { Intraocular pressure OD/OS }\end{array}$ & $20 / 20$ & $20 / 20$ & $20 / 20$ & $20 / 40 / 20 / 50$ & $20 / 20$ & $20 / 20$ & $20 / 20$ & $20 / 20$ \\
\hline$(\mathrm{mmHg})$ & $14 / 15$ & $13 / 14$ & $11 / 13$ & $11 / 11$ & $15 / 15$ & $14 / 15$ & $16 / 17$ & $11 / 12$ \\
\hline Lens & $\mathbf{N}$ & $\mathbf{N}$ & $\mathbf{N}$ & $\begin{array}{l}\text { Nuclear } \\
\text { opacity }\end{array}$ & $\mathbf{N}$ & $\begin{array}{l}\text { Cortical } \\
\text { opacity }\end{array}$ & $\mathbf{N}$ & $\mathrm{N}$ \\
\hline Iris & $\mathbf{N}$ & $\mathbf{N}$ & $\begin{array}{l}\text { depigmenta- } \\
\text { tion }\end{array}$ & $\mathbf{N}$ & $\mathbf{N}$ & $\mathrm{N}$ & $\mathbf{N}$ & $\mathbf{N}$ \\
\hline Vitreous & $\mathbf{N}$ & $\mathbf{N}$ & $\mathbf{N}$ & $?$ & $\mathbf{N}$ & $\mathbf{N}$ & $\mathbf{N}$ & $\mathbf{N}$ \\
\hline Amsler & $\mathbf{N}$ & $\mathbf{N}$ & $\mathbf{N}$ & $\mathbf{N}$ & $\mathbf{N}$ & $\mathbf{N}$ & $\mathbf{N}$ & $\mathbf{N}$ \\
\hline Perimetry & $\mathbf{N}$ & $\mathbf{N}$ & $\mathbf{N}$ & Contraction & $\mathbf{N}$ & $\mathbf{N}$ & $\mathbf{N}$ & $\mathbf{N}$ \\
\hline $\begin{array}{l}\text { Farnsworth 100-hue OD/OS } \\
\text { Retinopathy OD/OS: }\end{array}$ & $248 / 298$ & $174 / 216$ & $394 / 229$ & $108 / 45$ & $44 / 27$ & $50 / 48$ & $57 / 23$ & $107 / 57$ \\
\hline $\begin{array}{l}\text { Microaneurysms } \\
\text { Haemorrhages: }\end{array}$ & $-1 \leqslant 5$ & $\leqslant 10 / \leqslant 10$ & $\leqslant 10 / \leqslant 5$ & - & $-1<5$ & $-1 \leqslant 5$ & $-1 \leqslant 5$ & $\leqslant 5 /-$ \\
\hline $\begin{array}{l}\text { central } \\
\text { peripheral } \\
\text { Central retinal artery diastolic }\end{array}$ & - & - & $\begin{array}{l}\leqslant 5 / \leqslant 5 \\
\leqslant 10 / \leqslant 10\end{array}$ & $\begin{array}{l}\leqslant 5 / \leqslant 5 \\
\leqslant 5 / \leqslant 5\end{array}$ & $\begin{array}{l}- \\
\leqslant 10 / \leqslant 5\end{array}$ & $\leqslant 10 / \leqslant 10$ & - & $\begin{array}{l}\leqslant 5 /- \\
\leqslant 10 / \leqslant 20\end{array}$ \\
\hline pressure OD/OS $(\mathrm{mmHg})$ & $45 / 50$ & $35 / 36$ & $35 / 36$ & $40 / 42$ & $37 / 37$ & $36 / 37$ & $42 / 45$ & $35 / 35$ \\
\hline
\end{tabular}

$\mathrm{N}=$ no abnormality. 

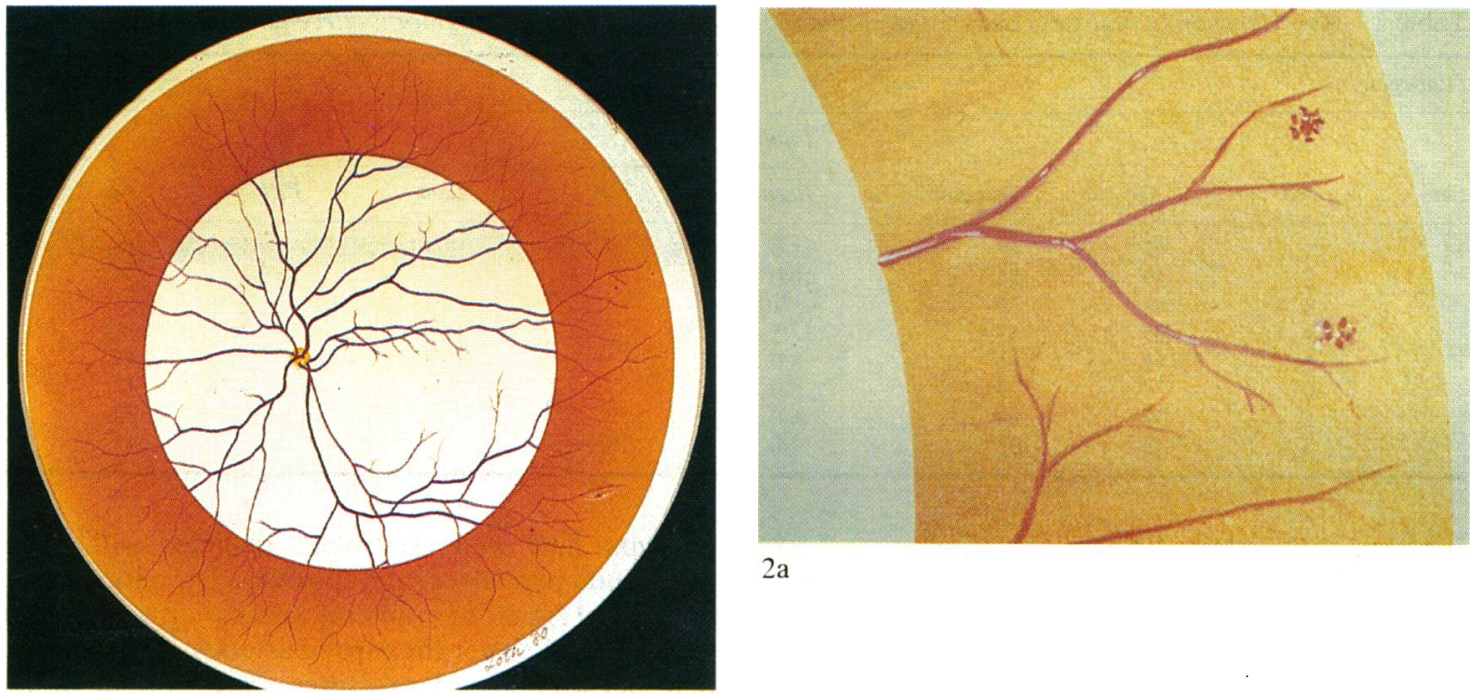

$2 \mathrm{a}$

1a

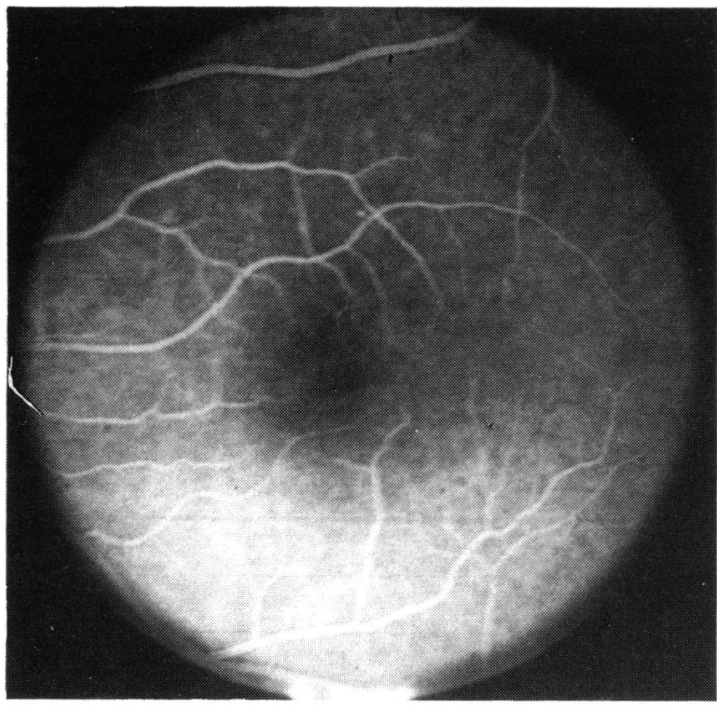

$1 \mathrm{~b}$

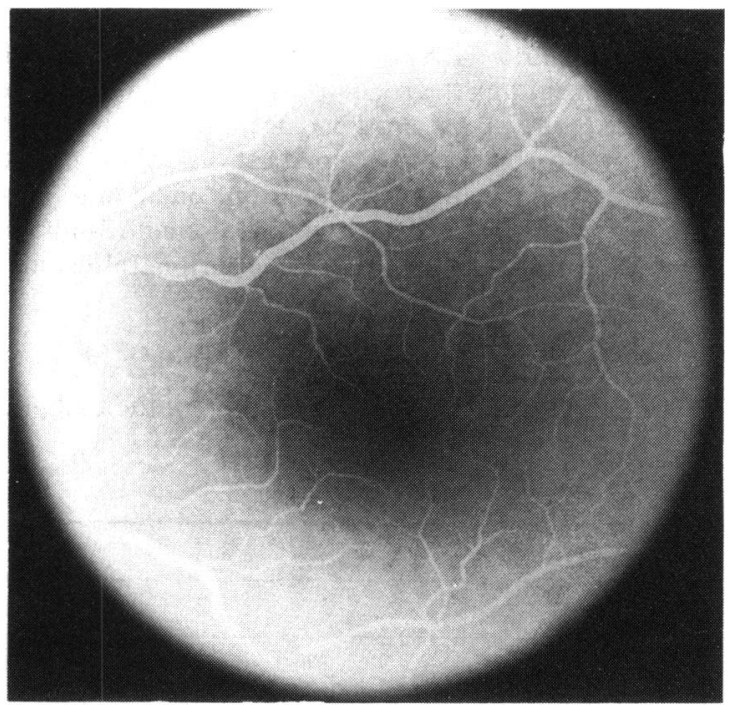

$2 b$

Fig. 1 Patient 1, OS. (a) Drawing of minute peripheral retinal haemorrhages at $12,2.30$, and 4 o'clock.

(b) Fluorescein angiogram of same eye showing one microaneurysm by conventional examination.

had bilateral diabetic pigmentary epitheliopathy of the iris. There was no evidence of posterior vitreous detachment or abnormal peripheral vitreoretinal adhesions. The state of the vitreous, however, was difficult to assess in patient 4 because of the lens changes. Patients 1, 2, and 3 showed high scores on

Fig. 2 Patient 6, OS. (a) Drawing of minute peripheral clustered retinal haemorrhages at 3 o'clock. (b) Fluorescein angiogram of same eve showing one microaneurysm by conventional examination.

Farnsworth 100-hue testing; errors were diffuse without precise axis.

The fundi of the 8 diabetics showed minimal positive findings with only aneurysms and haemorrhages (Table 2). The search for peripheral haemorrhages was a separate undertaking. They 
were seen in all the diabetics, and in patients 1,5,6,7, and 8 their presence in one eye was the only retinal abnormality. Drawings of these peripheral haemorrhages are shown for patients 1 and 6 (Figs. 1a, 2a). The only diabetic lesion at the posterior pole was one microaneurysm in the left eye of patients 1 and 6 (Figs. 1b, 2b). These haemorrhages (Figs. 1a, 2a) lay between the equator and the ora serrata, near the terminal divisions of arterioles and venules, more often near the venules. They were more frequently seen in the temporal quadrants but were found in all quadrants. Most were superficial, round, and punctiform, lying either isolated or grouped to give a granular appearance (Fig. 2a). A few were larger, oval, and of a darker hue, and a few were linear or fusiform. In this group of patients it was possible to find from 5 to 20 separate haemorrhages in the periphery of any one eye.

In none of the patients in the control group were haemorrhages seen in the periphery of the retina.

\section{Discussion}

The present finding of peripheral retinal haemorrhages with little or no retinopathy at the posterior pole has not to our knowledge been previously reported. It is rare to submit diabetic patients with no diabetic change at the posterior pole on direct ophthalmoscopy to extensive study of the periphery of the fundus. Furthermore, attention is usually directed towards the lesions at the posterior pole because of their functional consequences.

Because the extensive clinical and biological studies made in these 8 diabetics were normal, we may conclude that there were no systemic, ocular, or therapeutic causes, other than well controlled diabetes, to account for the presence of peripheral retinal haemorrhages. However, these patients are unusual in that all but one have survived more than 30 years of diabetes, and vascular complications are very mild.

Present photographic equipment did not allow reliable assessment of the fluorescein angiographic appearance of these very anterior lesions.

It is of course speculative to make generalisations from such a small group about patients with juvenileonset diabetes. However, it may be that peripheral retinal haemorrhages represent a breakdown of the blood retinal barrier at the peripheral vascular arcade where the retinal flow is the slowest, and the thin retinal tissue makes extravasation of blood easy and readily visible.

Our findings would tend to support Kohner's suggestion that diabetic lesions 'probably start in the periphery,'s though it is not certain that Kohner included lesions as peripheral as the ones reported here. In the literature large areas of capillary closure in the midperiphery of the fundus have been identified in association with proliferative retinopathy. ${ }^{2}$ Extensive acellularity of the peripheral retinal capillaries is found in retinal digest preparations from cases of advanced diabetic retinopathy. However, this may represent not a diabetic but a senile process which starts at an early age in the peripheral retinal vessels. ${ }^{6-8}$

Further studies are needed, particularly in diabetes of shorter duration or with other types of retinopathy, to confirm and to assess the significance of our findings and their relationship to the familiar diabetic retinopathy at the posterior pole.

We thank Dr Marliss's laboratory for measurement of the C peptide level. Madeline Ahad for careful typing. Sandy Singer for the photographs. and Heinz Loth for the fundus drawings.

\section{References}

1 Davis MD. Natural Course of Diabetic Retinopathy. In: Kimura SJ. Caygill WM. eds. Vascular Complications of Diabetes Mellitus. St Louis: Mosby. 1967: 139-69.

2 Kohner EM. Dollery CT. Diabetic Retinopathy. In: Keen H. Jarrett J. eds. Complications of Diahetes. London: Arnold. 1975: $7-55$.

3 Norton EWD. Gutmann F. Diabetic retinopathy studied by fluorescein angiography. Ophthalmologica $1965: 50: 5-17$.

4 Albisser AM. Leibel BS. Johnson W, et al. An improved technique for the rapid continuous measurement of whole blood glucose suitable for clinical application in an artificial endocrine pancreas. Med Progr Technol 1977; 5: 141-8.

5 Kohner EM. Diabetic retinopathy. In: Tattersall R, ed. Clinics in Endocrinology and Metabolism. New York: Saunders, 1977: 6: 345-75.

6 Wise GN. Dollery CT. Henkind P. The Retinal Circulation. New York: Harper and Row. 1971: 7.

7 Spitznas N. Bornfeld N. The architecture of the most peripheral retinal vessels. Albrecht von Graefes Arch Klin Ophthalmol 1977; 203: 219-29.

8 Asdourian GK. Goldberg MF. The angiographic pattern of the peripheral retinal vasculature. Arch Ophthalmol 1979:97:2316-8. 